\title{
Problematic issues of geographical education in Kazakhstan
}

\author{
Ordenbek Mazbayev ${ }^{1}$, Lazat Alieva², and Arman Demeuov, ${ }^{3, *}$ \\ ${ }^{1}$ L. N. Gumilyov Eurasian National University, 2 Satpayev Str., Nur-Sultan, 010008, Republic of Kazakhstan \\ ${ }^{2}$ Republican Physics and Mathematics School in the city Nur-Sultan, 2/1 Turkistan Str., Nur-Sultan, 010000, Republic of Kazakhstan \\ ${ }^{3}$ Abai Kazakh National Pedagogical University, 13 Dostyk Ave., Almaty, 050010, Republic of Kazakhstan
}

\begin{abstract}
Geographical education in the post-Soviet countries after independence is oriented to the Western model of teaching disciplines. What positive and negative results have been obtained to date are discussed in this article. In the last four years, the educational process in schools has been focused on an updated program. As a result, an interesting question arises: how do we teach students? And this question, what subject we are studying, is moved to the background. The mass transfer of school subjects to a new model of education led to disintegration. In this article, the authors try to analyze the state of geographical education in Kazakhstan, to characterize the process of studying geographical disciplines from the seventh to the eleventh grade. As the authors of the updated textbook, we found many inconsistencies and issues that need to be addressed immediately. There is a model of geographical education, using the material of the updated program to preserve the traditions accumulated over the years of geographical education and upbringing.
\end{abstract}

\section{Introduction}

The goal of the modern education system is to give the student the minimum of knowledge and skills that will allow him to start an independent life and are considered an initial step in the educational process and in the formation of a person. A school is a learning environment, and its core is the teacher. A teacher of a new formation must have spiritual, moral, and civic responsibility, characterized by a high level of reflexive, self-fulfilling methodological, research, and other competencies.

Within the framework of the results-based education model and the new management paradigm, there is a need for training aimed at developing the professional culture of teachers in order to master certain concepts and norms, and effective learning technologies.

Therefore, today the country's education system faces the task of providing the educational process with new content based on fresh ideas.

In the process of improving the quality of education and moving to a result-oriented model, teachers must have a highly informative and communicative culture with a high level of activity. To improve the quality of education in Kazakhstan, the State program of education development for 2011-2020 has been developed. The law on the status of a teacher was adopted [1]. In this regard, reforms and policies, changes and innovations in the country's education system can become the basis for each pedagogical community to think, reflect on the past and the present. Work with new ideas and face the problems of the updated program.

The main goal in the traditional education system is to ensure that it is result-oriented, based on the competence of the individual, to prepare the most qualified person and enter the world educational space.

The Concept of 12-year education in the Republic of Kazakhstan states that the main task of forming professional and personal competence of teachers is to possess the following competencies:

- special competence is the ability to predict your professional development;

- social competence is the ability to carry out professional activities;

- educational competence is the ability to use the basics of pedagogical and social psychology [2].

The program that we studied in today looks incomplete, so it needs changes and updates. Some would like to return to the Soviet system of education, in which everything was clear, but this is currently impossible. The main task of the school is not just to give children knowledge, but to teach them to apply their knowledge in practice in everyday life. We need to encourage students to get their own knowledge and search for information using the possibilities of digitalization. That's the point of the updated content.

If we want to teach children how to use their knowledge in everyday life, this should be done using examples of the subjects taught. There are various forms and methods. For example, developing projects, becoming experts and managers, working in groups, using the opportunities of tourist and local history,

\footnotetext{
${ }^{*}$ Corresponding author: arman demeuov@mail.ru
} 
environmental work, etc. Therefore, according to the requirements of the time, we must train and educate the younger generation using new methods. In our opinion, the method works when we have a good, well-thoughtout program of disciplines.

\section{Results and discussion}

According to the developers of the updated content of education program, it is aimed at improving four skills: listening, speaking, reading and writing. The four skills are closely related in the curriculum and are comparable to the "spiral method". The alleged spiral form of learning suggests that re-examining material that will become more complex throughout school education gives a greater advantage in the development of the modern student than traditional forms of learning. This option is questionable. We depart from the principle of what subject we study [3].

The authors suggest that training should be active, conducted in a collaborative environment, and that training should be differentiated in the educational process. Implementations must be implemented on intersubject links. The use of information and communication technologies (ICT) is mandatory. The standard curriculum for the subject "Geography" for grades 7-9 of basic secondary education according to the updated content was approved by the order of the Ministry of education of the Republic of Kazakhstan dated April 3, 2013 No. 115.

According to the standard program, a new-generation curriculum and textbooks have been developed.

The curriculum is developed in accordance with the State compulsory standard of secondary education (primary, basic secondary, General secondary education). The volume of the academic load on the subject "Geography" is:

1) in the 7th grade -2 hours a week, 68 hours in the school year;

2) in the 8th grade - 2 hours a week, 68 hours in the school year;

3 ) in the 9th grade - 2 hours a week, 68 hours in the school year.

The content of the subject includes 6 sections:

1) Methods of geographical research;

2) Cartography and geographical databases;

3) Physical geography;

4) Social geography;

5) Economic geography;

6) Country Studies with the basics of political geography.

These sections are studied in grades 7-9. As indicated in the program, the purpose of the textbook "Geography" in high school (grades 10-11) is to create conditions for students to apply geographical knowledge, skills and abilities aimed at solving geo-ecological, geoeconomic, social, geopolitical and global problems that arise at all levels of geographical space. For Example: Section 1. Methods of geographical research on the topic-current methods of geographical research, which set such goals:
11.1.1.1 - to apply elements of geographical expertise according to the research topic;

11.1.1.2 - to apply the methods of expert assessments according to the research topic;

11.1.1.3 - to apply modeling methods according to the research topic;

11.1.1.4 - to apply zoning methods according to the research topic.

The volume of the academic load on the subject "Geography" in the natural-mathematical and socialhumanitarian areas is:

1) in the 10th grade natural-mathematical direction (NMD) - 4 hours a week, social-humanitarian direction (SHD) - 3 hours a week of the school year;

2 ) in the 11 th grade NMD -4 hours a week, SHD -3 hours a week of the school year.

The content of the subject includes 7 sections:

1) Methods of geographical research;

2) Cartography and geoinformatics;

3) Environmental management and geo-ecology;

4) Geo-economics;

5) Geopolitics;

6) Country studies;

7) Global problems of humanity.

After looking at the layout of hours and sections, schoolteachers find it difficult to navigate the learning space. This is a fact. To date, textbooks for the updated program and it can be seen that content a lot of repetition and duplication. The geography of Kazakhstan is spread across sections from grades 7 to 11 . There are outstanding topical issues of geography on geoeconomics and country studies. There is no industry as tourism at all. The authors of the article wrote a class 11 textbook on the SHD for 102 hours. Therefore, we know enough about the disadvantages and positive aspects of the updated program.

At this time, there is an examination of textbooks of the $11^{\text {th }}$ grade. It was not possible to change or add additional paragraphs to the content because it was impossible to deviate from the approved program [4]. The authors of textbooks published geography textbooks for secondary schools in previous years. The requirements for the program were different, but in a specific example, the goals were met $[5,6,7]$.

The updated textbook is compiled in accordance with the requirements of the updated content of education.

The modernization of Kazakhstan's education, accompanied by the transition to the updated content of training, is aimed at improving the quality of training, a person-oriented approach to learning, and increasing motivation when studying specific disciplines. That is why the implementation of these recommendations in the educational process is becoming particularly relevant. Personal-oriented training, various variants of its implementation in the world practice and approaches to training-the essence of differentiation of training in its various manifestations is described in the work of E. S. Polat et al [8].

The modernization of the educational sphere is taking place against the background of deep political and socioeconomic transformations in the world and in Kazakhstan's society. Everything that is happening is 
connected with the transition to geopolitical and market relations.

The purpose of the subject "Geography" of the 11th grade is the development of functional literacy of schoolchildren, geographical knowledge, skills and abilities aimed at solving geo-ecological, geo-economic, social, geopolitical and global problems [9].

Skills acquired in grades 7-10 become more complex over time and become applied in grade 11 .

The main objectives of the subject are:

1) development of geographical and spatial thinking, understanding of global, regional and local approaches, especially in the areas of geo-ecology, geo-economics and geopolitics;

2) creating conditions for the use of modern methods of processing GIS data in the study of country studies and global problems of mankind;

3 ) using the acquired knowledge and skills in the subject "computer science", implementation of practical work and tasks that are in the textbook;

4) professional orientation of students by performing various activities related to geospatial methods and data.

The training material is designed in such a way as to develop students' scientific, logical, informative speech. The tasks presented in the textbook are mostly practiceoriented in nature and on they are aimed at developing research skills, logical thinking, memory, observation, and individual personality traits.

Teachers will be able to implement results-based learning, organize independent search activities for students, and objectively measure the levels of development of functional literacy of each student on all subjects of the subject, using the structure and evaluation mechanism proposed in the form of a criteria-based evaluation system.

The purpose of this manual is to provide practical assistance to the teacher in the development of thematic planning for geography class based on the updated content of education, plans of lessons, and of guidance in the selection of pedagogical techniques, method, approach, strategy, etc.

The authors hope that this publication can be used for a creative approach to their work by each interested teacher and will allow, if necessary, a flexible approach to the structure of the lesson, to diversify the methods and techniques of teaching, as well as the content of working with students.

The training manual for students offers the following forms of work:

- independent understanding of the main educational and additional material;

- preparation of reports-messages, abstracts, presentations in the PowerPoint program, preparation and presentation of posters, clusters, maps, etc.;

- project, practical, research, creative activities;

- independent, individual and group work.

The content of the training manual is designed to develop logical thinking in students, the ability to compare, analyze, generalize, evaluate, which will undoubtedly lead to the assimilation and consolidation of the acquired knowledge on the subject without mechanical memorization, as well as the education of students responsible attitude to learning and culture of mental labor.

The training manual was developed by practical teachers and scientists who are well aware of the theoretical material and age characteristics of students.

The authors hope that this guide will help geography teachers in their creative and practical work.

Almost all tasks motivate students to independent and research activities.

Structure of the training manual:

- Scientific and methodological foundations of the course "Geography" of the $11^{\text {th }}$ grade (pedagogical strategies, technologies, methods and techniques of training).

- Methodological features of applying the matrix method in geographical research.

- Goal setting in geography lessons.

- Requirements for students' activities.

- Calendar and thematic planning for the subject "Geography" of the $11^{\text {th }}$ grade.

- Examples of short-term lesson planning developments.

The updated content of the course "Geography" of the $11^{\text {th }}$ grade provides a comprehensive, systematic and socially oriented approach to understanding nature, natural phenomena, socio-economic processes and patterns, and integration processes taking place between countries. Studying geography, students should get an idea of the relationship and interaction of society, economy and nature.

The content of the training material is directed:

- to develop the ability to analyze, systematize and argue your answers;

- to create conditions for organizing and conducting research to motivate students to self-development;

- analysis of the political and geopolitical situation, geoeconomics of countries and the ability to solve environmental and other problems using materials about the country or area.

The guiding ideas of the textbook's methodological model are the principles:

- visualizations;

- availabilities;

- awareness and activity;

- strength of knowledge;

- scientific character;

- links between theory and practice;

- naturalness;

- educational training;

- developing training [10].

Students master the techniques of comparison, generalization, abstraction, classification, systematization, analysis, and synthesis when performing tasks. Special attention should be paid to those teaching methods where it is necessary to prove the truth of the proposed position, to argue theses, to highlight the main idea, to distinguish between essential and secondary features, to draw conclusions based on the analysis of actual material. Mental development is influenced by the application of knowledge, skills and 
abilities in practice, with the optimal combination of creative and reproductive methods.

The text of the textbook uses various technologies, types of exercises (research, presentations, creative tasks), individual and group forms of work, and creates important prerequisites for the broad disclosure of individual characteristics of each student.

With the help of the structure and mechanism of the criteria-based assessment system specified in this methodological guide, it is possible to carry out developmental training focused on results, organize independent search activities of students, and carry out training in all sections of the discipline, namely:

1) methods of geographical research

2) cartography and geoinformatics

3) environmental management and geo-ecology

4) geo-economics

5) geopolitics

6) country studies

7) global problems of humanity

Each student can objectively assess the level of functional literacy development based on the knowledge gained in grades 9-10.

The difference between the teaching technology "Three-Dimensional methodical system" (TMS) and others is the three-dimensionality of all components of the methodological system (goals, content, methods, forms and means). Each component of the methodological system has a hierarchical relationship with each other. First of all, the goals of the three levels of development arise independently of each other. Intermediate results that are gradually achieved are put in the intended form (to measure a certain number of points). In accordance with the goals of each level, a sequence of level test tasks is selected that complement, deepen, and complicate [11].

Goal setting in geography lessons is one of the most problematic stages of pedagogical activity. Under the goal statement, we must understand that the goal is a model of the result.

1. Knowledge is the result of the process of cognitive activity of students. Knowledge means only the result of knowledge that can be logically or actually justified.

2. Category - memorizing and reproducing the studied material - from concrete facts to a complete theory.

3. Understanding is a universal thinking associated with the assimilation of new content. This category indicates the transformation of the material from one form of expression to another, the interpretation of the material, the assumption of the further course of the event-explains the facts, rules, and principles.

4. Application - the ability to use the learned material in specific conditions and new situations.

5. Analysis - geographical analysis - allows you to compare a variety of spatial information and present the results of the analysis in a form that is easy to understand.

6. Synthesis is the process of joining or combining previously disparate concepts into a whole. This category refers to the ability to combine elements to get a whole that has novelty.
7. Evaluation - indicates the ability to evaluate the value of a particular material.

The use of TMS technology in the learning process and the use of Bloom's taxonomy (Fig. 1) allow us to achieve positive results, in particular, students:

a) master the skills of self-study using the research method;

b) must be evaluated for each group. To do this, at the end of the lesson, three-level test tasks are performed that complement each other, deepen and complicate.

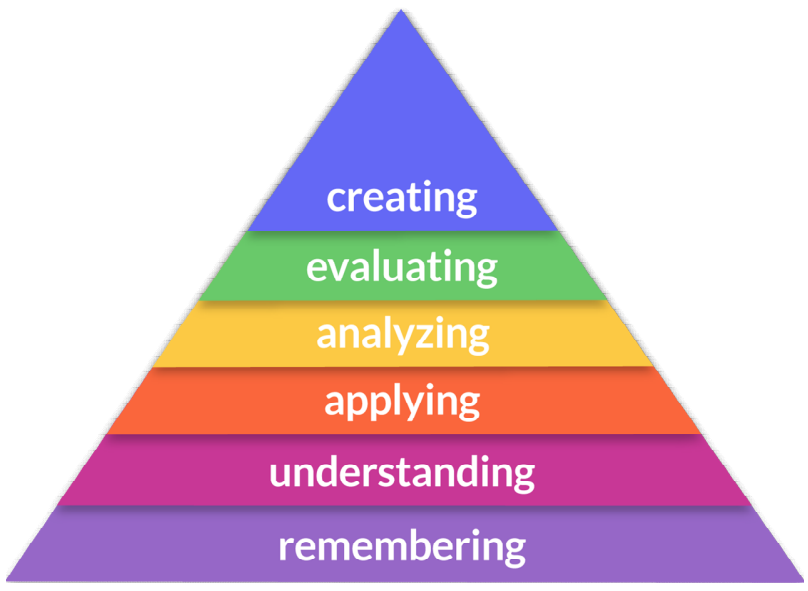

Fig. 1. Bloom's taxonomy of educational goals in the cognitive sphere [12].

In the course of completing the task, the student will get the appropriate score, depending on their ability.

With the traditional and correct completion of all tasks of the first level, he will receive 5 points, for the second level -4 points, for the third-3 points. Having scored 12 points in the sum, his level of knowledge corresponds to the rating of "five". When performing SOR and SOC, there must be feedback between the student and the teacher. A corresponding score is given for each topic. A distinctive feature of this training technology is the "three-dimensional methodological system".

As a result, each student:

- receives a guarantee for alternative training;

- describes the ability of the students;

- a talented child gets the opportunity for all-round development;

- increasing interest in learning by gaining points on the "plus" rating system (based on the new qualimetry).

If in traditional education the primary role in the educational process is played by the teacher, now the student is active, i.e. he is trained by himself. In traditional teaching, the teacher provides the appropriate information to the student, and the student only listens and perceives the material. In the classroom, most often used reproductive methods (lecture, question-answer, exercise, etc.).

Currently, the student is looking for himself, he is learning. The lesson provides problem-based learning (solving the situation, thinking the child, "brainstorming", debates, etc.). At the lesson, the teacher performs a managerial role, orienting students. 
The main attention is paid to identifying individual opportunities, research abilities, taking into account the interests of each student.

The student's activity is evaluated by many personal qualities (intellectual development, speech culture, independence, self-regulation, initiative, responsibility, etc.). Each student is compared to himself, not to another student. The student is given the opportunity to selfevaluate.

In this technology, both individual and group forms of training are the main ones. The main goal of group learning is to attract students to work together in small groups. In such a group, the student does not lose his identity. If necessary, students can turn to each other for help, solve common problems, i.e. there is a process of mutual learning. During the lesson, each student can not only evaluate their achievements or understand their shortcomings, but also see how they affect the overall result.

The individual form of training allows students to perform certain tasks and teaches them to be responsible for the result of completing tasks in front of themselves and the teacher. Such forms of training develop the student's self-confidence, stimulate the personal quality of honor and self-esteem.

With the development of a schedule for this technology, it is necessary to divide all topics into modules.

A module is a large, large-scale topic or Chapter consisting of several paragraphs. The peculiarity of this planning is that each Chapter (or module) ends with three final sessions:

- thematic independent work consisting of level tasks;

- correctional work;

- control work consisting of level tasks.

\section{Step 1: "know task"}

- be able to read a map;

- mastering the program for creating diagrams, tables, etc. from the computer science course;

- ability to describe and characterize the geographical position of countries;

- knowledge of geographical and geopolitical terms.

Step 2: "understanding task"

- understanding the purpose of the types and methods of research;

- why is it important to explore the territory of countries;

- why do political maps change;

- what factors influence the development of countries and territories.

Step 3: "application task"

- use of aerospace imagery and mapping techniques;

- use of conventional signs and symbols for zoning and modeling of topics and research objects;

- use of various programs to perform practical work; - assessment of the geographical and geopolitical situation of individual countries using GIS technology.

\section{Step 4: "analytic task"}

- using tables and maps of the textbook, analyze geoeconomics, geopolitics of the countries of the world and Kazakhstan;

- creating a database, conducting zoning and modeling, give a comprehensive analysis of the research topic.

\section{Step 5: "synthesis task"}

- applying different methods of training, identify gaps and opportunities to identify prospects and prediction;

- as a result of practical work, draw conclusions and make recommendations.

\section{Step 6: "evaluation task"}

- during expert evaluation, determine the objectivity and correctness of problem solving, which is evaluated by the teacher or by the students themselves;

- individual and group work.

Special attention is paid to the preparation of control and measurement materials, the use of information and communication technologies (ICT), working with internet resources, etc. As a result, the ability of students to competently and creatively use information and communication technologies in the educational process, in their free time and when communicating is ensured. The new training model implies the widespread use of ICT in various forms: test cases, training programs and platforms, electronic resources, and the Internet. The urgency of the transition to new forms of education based on the principles of using computer technologies is also emphasized [13].

Students develop skills for searching, processing and producing information, exchanging data and ideas, interacting, evaluating, and improving

Its work with various hardware and applications. For the purpose of studying the discipline, the following interactive classes are provided: business game; casetechnologies; work in small groups. It is also recommended to organize meetings with scientists, travelers, and employees at the factory.

The teacher needs to be creative in their work, adapt to the structure of the lesson, modify methods, and use auxiliary tools that include working with students.

Students are offered the following types of work: - independent understanding of the main educational and additional material;

- preparation of a message-report, abstract, PowerPoint presentation, poster, cluster, map diagram;

- project, practical, research, creative activities;

- independent, individual, paired work.

\section{Conclusions}

The educational and methodical complex is prepared by practical teachers and scientists who are well aware of the age characteristics of students.

This educational complex is innovative in nature, meets the requirements of modern society in the system of new knowledge in the education and comprehensive development of the individual.

There are also positive aspects of the program. Through personal and social development, students will learn to define, revise, and evaluate the values of society and personal values. They will also develop skills that will allow them to evaluate their own abilities, work independently, as well as in a team and make decisions. But the content of the curriculum is not worked out, because they noticed a discrepancy in the distribution of hours by section. The section "Nature management and 
geo-ecology" occupies a third of the content. The educational program requires the following skills from the teacher:

- formulate training goals to achieve results;

- build a learning process for the organization of learning materials;

- prepare training materials in accordance with the training goals;

- use the potential of the information environment for the educational process;

- create conditions for the advanced development of students in the personal and activity orientation;

- evaluate current results aimed at achieving the set goals;

- to lead them to find ways to solve the problem that has arisen in front of them;

- conduct and prepare the educational process, so that all individual abilities of students are taken into account;

- use more tasks so that they work in groups and in pairs;

- make multi-level questions so that they approach the issue in more depth;

- a more serious approach to developing students' critical thinking. Thus, the author's collet, who wrote a textbook on the updated program, paid special attention to the development of a methodological guide, taking into account the above. Educational and methodical complex on geography of the $11^{\text {th }}$ grade, tested in order in eighty schools of the Republic of Kazakhstan.

In this period, the main drawbacks are writing textbooks strictly according to the program. Do not allow authors to include certain aspects of educational geography.

Despite the ubiquity of digitalization, there is a weak material and technical base of schools. During testing of new generation textbooks, schools found limited access to the Internet and multimedia and office equipment, outdated equipment, and incomplete equipment

According to teachers, at the initial stage, there is a decrease in academic performance. Some students are disorganized because from grades 7 to 11, topics and sections are repeated. As a result, students have little knowledge of the basics of geography such as geographical patterns, Geology, tectonics, and cartography. Especially the sections Geoinformatics, geo-economics, geopolitics are mastered with difficulty. Below we attach the content of the author's updated textbook of the 11th class of the SHD:

The introduction of the updated content of secondary education did not take into account the training and retraining of schoolteachers. Short-term courses on the open program did not give the desired result.

The transition to the updated program will require the modernization of the entire education system. In order to make this transition, we need to start the changes with ourselves and with the training of teaching staff in educational institutions.

The system of geographical education in schools and universities that has developed in Kazakhstan over the past five years, especially now, is in a state of disintegration, which is manifested in connection with the introduction of an updated program in secondary schools without taking into account the readiness of teachers and schools themselves.

If until recently, the main complaint of teachers was the incompleteness of school geographical education, which is illogically distributed among classes, in particular, the very principle of teaching geography, we ask the question - what exactly it should be.

In view of the current situation and according to the authors of teachers-practitioners of geography, the geographical model of education should have the following structure.

- in grade 7, study the basics of physical and economic geography;

- in the $8^{\text {th }}$ grade study of physical geography of Kazakhstan;

- in the $9^{\text {th }}$ grade study of economic and social geography of Kazakhstan;

- in the $10^{\text {th }}$ grade geo-economics (world) and Geoecology;

- in the 11th grade, country studies and global problems of humanity.

Starting from the 2020-2021 school year, students will be engaged in the expanded program. Thus, from grade 7 to grade 11, textbooks were written, and courses were developed. Thus, the updated program cycle will be fully implemented. The authors suggest that starting from the 2021-2022 academic year, it is necessary to update the content of the program according to the new structure. In the Republic, textbooks for grades 8-9 are available, but it is necessary to make an adjustment in accordance with the program. For the 10th grade, it need to write a new textbook on geo-economics and geoecology, as well as for the $11^{\text {th }}$ grade. There are 3-4 years to write these textbooks. We believe that the use of research methods in high school will be justified. In grades 7-8, the section "Methods of geographical research" causes difficulties in understanding.

The authors understand that the proposed structure of geographical education will cause controversy, so offering this structure, we are waiting for rational proposals. We want to solve and find an answer to some questions from the current situation.

Modernization of Kazakhstan's education, accompanied by the transition to the updated content of training, is aimed at improving the quality of training, a personal-oriented approach to learning, and increasing motivation in studying specific disciplines. That is why the implementation of these recommendations in the educational process is particularly relevant.

The modernization of the educational sphere is taking place against the background of deep political and socioeconomic transformations in the world and in Kazakhstan's society. Everything that is happening is connected with the transition to geopolitical and market relations. The task of methodologists from near and far abroad is to study the experience of geographical education and apply it in the educational process of their countries. 


\section{References}

1. Law on the status of a teacher of the Republic of Kazakhstan (No. 293 of December 27, 2019) https://cis-

legislation.com/docs_list.fwx?countryid $=005 \&$ page $=1$. Accessed 4 Feb 2020

2. Concept of 12-year Secondary education of the Republic of Kazakhstan Astana (ME of Kazakhstan, Astana, 2010)

http://www.gov.kz/memleket/entities/edu?lang=kk/. Accessed 2 Feb 2020

3. R.S. Bajbulatova, Plyusy ' $i$ minusy obnovlennogo soderzhaniya obrazovaniya (The pros and cons of the updated content) (2019), http://sc0004.zharkain.aqmoedu.kz/news/open/id314842. Accessed 5 Feb 2020

4. Decree of the President of the Republic of Kazakhstan dated December 7, 2010 No.1118 “On approval of the State program of education development of the Republic of Kazakhstan for 2011-2020",

https://online.zakon.kz/document/?doc_id=3090691 5. Accessed 24 Jan 2020

5. L.N. Aliyeva, G.A. Uteeva, N.E. Krupina, Uchebnik "Geografya" dlya 11 klassa sotsialnogumanitarnogo napravlenia s russkim yazykom obucheniya ("Geography" textbook for the 11th grade of the social and humanitarian direction with the Russian language of instruction). (Arman-PV, Astana, 2015)

6. L.N. Aliyeva, G.A. Uteeva, N.E. Krupina, "Geografya" dlya 11 klassa yestestvennomatematicheskoe napravlenia s russkim yazykom obucheniya ("Geography" textbook for the 11th grade of the natural-mathematical direction with the Russian language of instruction). (Arman-PV, Astana, 2015)

7. L.N. Aliyeva, G.A. Uteeva, Rabochaya tetrad "Geografya" dlya 11 klassa sotsialnogumanitarnogo napravlenia s russkim yazykom obucheniya ("Geography" workbook for students of the 11th grade of the social and humanitarian direction with the Russian language of instruction). (Arman-PV, Astana, 2015)

8. E. Polat, M. Bukharkina, A. Petrov, Novy'e pedagogicheskie $i$ informaczionny'e tekhnologii $v$ sisteme obrazovaniya (New pedagogical and information technologies in the education system). (Akademiya, Moscow, 2009)

9. S. Bylinskaya, G. Chistyakova, S. Tulepbekova, G. Zhapanova, Geografiya. Metodicheskoe posobie dlya uchitelej 10 klassa srednej shkoly ' Geography. Methodical guide for teachers of the 10th grade of secondary school). (Almaty, 2018)

10. M.-C. Esi, The didactic principles and their applications in the didactic activity. Sino-US English Teaching 7(9), 24-34 (2010)

11. Zh.A. Karaev, IJEE 11(2), 19-25 (2013)
12. T. Dawson, Bloom's Taxonomy, VCoL \& the Lectical Scale (2019), https://medium.com/@theo_dawson/bloomstaxonomy-vcol-the-lectical-scale-d7851729ab2b. Accessed 27 Jan 2020

13. E.N. Zvereva, O.V. Kharitonova, Stat. Econom, Inform. 3, 3-5 (2015) 